\title{
The use of argatroban as an anticoagulant for cardiopulmonary bypass in cardiac operations
}

\author{
Kojiro Furukawa, MD, ${ }^{a}$ Hitoshi Ohteki, MD, ${ }^{a}$ Kenji Hirahara, MD, ${ }^{b}$ Yasushi Narita, CE, and Shugo Koga, MD, \\ Saga, Japan
}

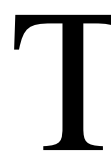
he anticoagulant effect of heparin is dependent on the level of antithrombin III (AT III). Argatroban (Novastan; Mitsubishi Tokyo Chemical Corporation, Tokyo, Japan) is a unique synthetic direct thrombin inhibitor developed in Japan. ${ }^{1}$ Argatroban requires no AT III to exert its antithrombin effect. ${ }^{2,3}$ We used this drug as an anticoagulant during cardiopulmonary bypass (CPB) in a patient with AT III deficiency.

\section{Clinical Summary}

A 44-year-old man was transferred to our hospital with shock and multiorgan failure on December 31, 1999. Laboratory studies of

From the Departments of Cardiovascular Surgery ${ }^{\mathrm{a}}$ and Emergency Medicine, ${ }^{\text {b }}$ Saga Prefectural Hospital, Koseikan, Saga, Japan.

Received for publication March 21, 2001; accepted for publication April 24, 2001

Address for reprints: Kojiro Furukawa, Department of Thoracic and Cardiovascular Surgery, Saga Medical School, 5-1-1 Nabeshima, Saga City 849-8501, Japan (E-mail: furukawk@ post.saga-med.ac.jp).

J Thorac Cardiovasc Surg 2001;122:1255-6

Copyright @ 2001 by The American Association for Thoracic Surgery

$0022-5223 / 2001 \$ 35.00+0 \quad \mathbf{1 2 / 5 4 / 1 1 6 9 4 0}$

doi: $10.1067 / \mathrm{mtc} .2001 .116940$ his blood revealed severe liver dysfunction probably due to fulminant hepatitis. Echocardiography revealed severe aortic regurgitation and vegetations on the aortic valve, and infective endocarditis was diagnosed. Continuous hemodialysis and filtration for renal failure were performed for 12 days and plasma exchange for hepatic failure was performed twice. Gradually, his general condition improved. Aortic valve replacement was scheduled for March 21,2000 . A preoperative echocardiogram showed that the left ventricular diameter was $67.0 \mathrm{~mm}$ during diastole and $43.3 \mathrm{~mm}$ during systole, and the left ventricular ejection fraction was $63.6 \%$ with severe aortic regurgitation. Liver dysfunction including coagulopathy (prothrombin activity $67.4 \%$, activated partial thromboplastin activity $<20.0 \%$ ) and AT III deficiency $(46.4 \%)$ persisited. Heparinization with AT III substitution therapy was discussed. However, if this therapy was used for anticoagulation during CPB, we believed that AT III and coagulant factors would be consumed and pathologic thrombosis or bleeding tendency would occur. ${ }^{4}$ After obtaining informed consent, we decided to use argatroban as an anticoagulant during CPB.

The extracorporeal circuit consisted of a roller pump, a silicone membrane artificial lung (HPO-20RHF-C; Senko Ika, Tokyo, Japan), and a hard reservoir. These components were connected with a heparin-coated polyethylene tube. No argatroban was added to the pump prime. A bolus injection of argatroban, $0.1 \mathrm{mg} / \mathrm{kg}$, followed by a continuous infusion at 5 to $10 \mu \mathrm{g} \cdot \mathrm{kg}^{-1} \cdot \mathrm{min}^{-1}$, was 


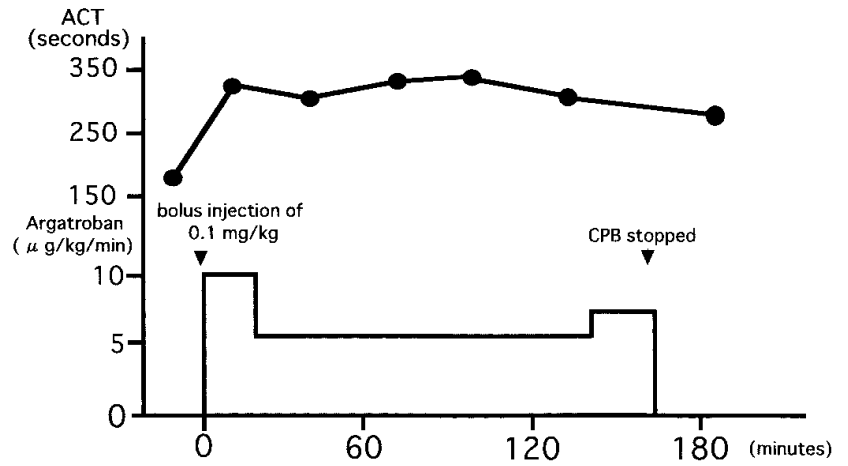

Figure 1. Dose of argatroban compared with activated clotting time. ACT, Ativated clotting time; $C P B$, cardiopulmonary bypass.

used. After the bolus injection, CPB with mild hypothermia was started. A conventional aortic valve replacement was performed with a stented porcine valve. The CPB and aortic crossclamp times were 167 and 114 minutes, respectively. During CPB, the dose of argatroban was adjusted to maintain the activated clotting time (ACT; Hemochron, International Technidyne Corporation [ITC], Kent, United Kingdom) between 300 and 400 seconds (Figure 1). Argatroban was stopped at the termination of CPB. Hypoxia and pathologic thrombosis did not occur during CPB. However, after $\mathrm{CPB}$, a small thrombus in the reservoir was recognized. The ACT 1 hour after CPB was 278 seconds. Only 2 units of packed red blood cells were transfused. Postoperative bleeding through chest tubes was $350 \mathrm{~mL}$ per day. Seven hours postoperatively, the ACT had returned to the control level. The postoperative course was uneventful. Chest tubes were removed on postoperative day 3 , liver and renal function did not worsen, and the patient was discharged on the 60th postoperative day.

\section{Discussion}

Heparin is widely used as an anticoagulant for cardiac operations. However, heparin is difficult to use in patients who have heparininduced thrombocytopenia, who are allergic to protamine surfate, or who have low levels of AT III. Especially in patients with heparin-induced thrombocytopenia, reexposure to heparin is associated with a high risk for the development of arterial and venous thrombosis. An ideal substitute for heparin during cardiac operations is being sought for those patients.
Danaparoid sodium and hirudin are the main substitutes for heparin currently available for anticoagulation during heart surgery. However, potential disadvantages of their use include difficulty in monitoring anticoagulant levels and irreversible effects. Argatroban ([2R, 4R]-4-methyl-1-[N-(3-methyl-1,2,3,4 tetrahydro-8-quinolinesulfonyl)-L-arginyl]-2-piperidine carboxylic acid) is a low-molecular-weight arginine derivative that binds thrombin competitively. ${ }^{1}$ Compared with heparin, hirudin, and danaparoid sodium, argatroban has several potential advantages. ${ }^{2}$ It does not need AT III as a cofactor, and it is non-antigenic. The anticoagulant effect is concentration-dependent, compromises both free and clot-bound thrombin, and exhibits no interaction with platelets or heparin antibodies. ${ }^{2}$ In addition, ACT can be used to monitor the anticoagulant effect. $^{3}$ The only clinical disadvantage that we observed is that no neutralizing agent exists, such as protamine for heparin. However, the fact that the plasma half-life of argatroban is as short as 15 to 30 minutes compensates for the lack of a neutralizing agent. ${ }^{3}$ We have been investigating argatroban as a potential anticoagulant in CPB experimentally ${ }^{2}$ and we have been using it in various clinical situations. ${ }^{3}$ From these results, we judged that argatroban is a potential anticoagulant in cardiac operations. In this case, we used argatroban because of the patient's AT III deficiency and severe liver dysfunction. We based our decision on our prior experiences and on the report by Matsuo's group, ${ }^{4}$ which states that argatroban deserves consideration as an anticoagulant drug whenever patients with AT III deficiency are likely to require an anticoagulant in the extracorporeal circuit. There have been no adverse effects due to argatroban. However, an ACT of more than 400 seconds may be optimal for cardiac operations because of small thrombi in the hard cardiotomy reservior.

\section{References}

1. Okamoto S, Hijikata A, Kikumoto R, Tonomura S, Hara H, Ninomiya $\mathrm{K}$, et al. Potent inhibition of thrombin by the newly synthesized arginine derivative No. 805: the importance of stereo-structure of its hydrophobic carboxamide portion. Biochem Biophys Res Commun. 1981;101:440-6

2. Sakai M, Ohteki H, Narita Y, Naitoh K, Natsuaki M, Itoh T. Argatroban as a potential anticoagulant in cardiopulmonary bypassstudies in a dog model. Cardiovasc Surg. 1999;7:187-94.

3. Ohteki H, Furukawa K, Ohnishi H, Narita Y, Sakai M, Doi K. Clinical experience of argatroban for anticoagulation in cardiovascular surgery. Jpn J Thorac Cardiovasc Surg 2000;48:39-46.

4. Matsuo T, Yamada T, Yamanishi T, Kodama K. Choice of anticoagulant in an antithrombin III (AT III)-deficient patient with chronic renal failure undergoing regular haemodialysis. Clin Lab Haematol. 1989; 11:213-9. 